Review Article

\title{
Integrating Information and Communication Technologies Into Second and Foreign Language Teaching: Pedagogical Benefits and Considerations
}

\author{
Nguyen Thanh Mai* \\ School of Foreign Languages, Hanoi University of Science and Technology, \\ No. 1 Dai Co Viet, Hai Ba Trung, Hanoi, Vietnam \\ Received 05 April 2020 \\ Revised 28 April 2020; Accepted 06 May 2020
}

\begin{abstract}
The article aims to review existing literature on the pedagogical benefits as well as considerations regarding the integration of Information and Communication Technologies (ICTs) into second and foreign language teaching. Greater collaboration and interaction, enhanced motivation and access to a huge repository of web-based materials are among the most popular advantages of ICTs. At the same time, ICT-integration into language teaching can be challenging due to the emergence of "multiliteracies" and the not-so-ICT-competent students in the language classroom. Besides, there are language teachers who fear that their professional identity could be disrupted as they try to adopt new technologies in their teaching. However, the review also points out that technologies do not automatically result in any remarkable pedagogical benefits without teachers' selective use. It is the teachers who enlarge the potentials of ICTs in promoting meaningful interactions and real intercultural reflections beyond the conventional language classrooms.
\end{abstract}

Keywords: ICT-integration, language teaching, pedagogical benefits, considerations, teachers" role.

\section{Introduction}

As the world enters the 21th century, more and more profound impacts of globalization have been observed in almost every aspect of our society ranging from politics, socioeconomy to culture. Globalization has also brought about changes in the field of education,

\footnotetext{
* Corresponding author.

E-mail address: mai.nguyenthanh@ @ust.edu.vn

https://doi.org/10.25073/2588-1159/vnuer.4401
}

the most inevitable of which is a push for using Information and Communication Technologies (ICTs) in the educational realm worldwide [1]. Initiated by the developed English-speaking countries including Australia, Britain, and U.S [2], this fundamental shift in education policy quickly spreads to many other non-English speaking countries, including Vietnam. Given the potential merits of creating a highly skilled workforce [3] competent in using technology and English as "two inseparable mediational tools" [4, p.1], integrating ICTs into education 
is not at all a simple process, especially in countries where English is not the first language such as Vietnam.

\section{Information and Communications Technology- Integration Into Language Teaching: Pedagogical Benefits}

Technology and Internet have transformed our education and communication. Celsi \& Wolfinbarger [5] detailed the adoption of ICT in education in three major stages, also referred to as the three waves, which are summarized as follows:

- Wave 1 - Technology as a support function: Technologies were used as supporting tools in teaching, providing students with practical experiences. Typical examples include the use of transparencies and overhead projectors. However, these innovations were rather limited and not directly student facing.

- Wave 2 - Mirroring: More directly student-facing technologies such as presentation software (e.g. PowerPoint), email and discussion groups helped "mirror" teaching functions and communication with students (e.g. making announcements or posting grades). Still, these did not lead to any major "behavioral or structural change in the classroom or classroom outcomes" (p.65).

- Wave 3 - Discontinuous innovation: This wave occurred with the introduction of new technologies or fundamentally new ways of using existing technologies. Asynchronous learning made possible by the Internet and Computer-based technologies (CBT) (e.g. video streaming, email and discussion tools) as well as collaboration tools (e.g. Web board and Blackboard) have created new and interactive classroom experience well beyond mirroring.

ICTs in education, especially language teaching, has been growing in significance as they continuously help extend class boundaries through increased interaction. First, students are given more opportunities to interact and collaborate in an ICT-enhanced learning environment compared to the traditional language classroom. Virtual community formation as the result of technology and
Internet are advantageous in allowing for, besides self-representation and friendship, students' interaction and negotiation of meanings with peers and teachers through researching topics, posting information, and probing comments $[6,7]$ in their own time and place [8].

Second, the use of technologies in parallel with language learning largely increases motivation [9]. For students, it is the new experiences learning with the technologies that keep them excited $[8,10]$. One very typical example can be seen in the use of virtual reality apps which allow students to build interactive and interesting creations, upload photos to share their experiences or leave additional comments or tips on a certain place [11]. For teachers, it is often the interest in using advanced ICTs to yield simulations for students to learn more practical educational skills [12].

Third, ICT applications make a huge number of resources on the Internet, in the media and in popular culture, become viable for language learners [6]. Web-based documents, which are mostly in English and cover a variety of subject matters, offer "a rich database of authentic materials" [13, p.374] which is ideal for language teaching and learning $[14,15]$. In short, employment of ICTs creates optimal conditions for language teaching and learning in which participants are highly motivated, engaged in meaningful interactions and negotiations and frequently exposed to "the types of text they will most probably encounter beyond and outside the course" [16, p.30].

\section{Information and Communication Technologies and Curriculum Innovation: What to Consider?}

Although research conducted in different parts of the world has emphasized on the promising potentials of ICTs in education, it does not mean the conclusion will hold true through different research contexts. Ideally, studies would lead to positive results as in Gómez, Meneses and Díaz's [17] where most students believed the introduction of ICTs 
in classroom was important, interesting and enhanced motivation. In fact, quite an opposite phenomenon has also been observed. For instance, Genç and Aydin's research [18] with 126 EFL students of the Preparatory School of Foreign Languages revealed a considerable number of learners who did not seem to be strongly motivated toward the technologyenhanced learning process. In another study by Hara [19], students who took part in the web-based course at a major US university even reported their distressing experiences due to communication breakdowns and technical difficulties.

Negative attitudes towards ICTs were also found among teachers although very few studies examined teachers' perspectives and emotional challenges involved in the integration of ICTs into language teaching. Bauer \& Kenton [20] pointed out that despite being highly educated, innovative and skilled with technology, the 30 teachers participated in their study didn't consistently use technology as both a teaching and learning tool because of the extra planning time for technology-enhanced lessons. Such findings were consistent with those of more recent studies [21, 22]. The teachers in Azzaro and Agudo's [22] research experienced, on the one hand, "genuine enthusiasm, curiosity and passion towards the implementation of ever changing teaching practices based on technology" and, on the other hand, unpreparedness and worries because of the "daunting mass of inscrutable and often unmanageable possibilities" [p. 194]. Lack of training and on-the-job refresher courses [22] as well as institutional support [21] would exacerbate the problem. These diverse attitudes and reactions towards ICT-integration underline a range of individual, practical and cultural factors that we have to take into accounts when designing any technology-enhanced curriculum.

\subsection{The Emergence of "Multiliteracies" in Language Classrooms}

The concept of multiliteracies, stated Baguley et al [23], emerged as a consequence of "the multimodal cross-cultural nature offered by digital communication media" (p.5). Along with the robust integration of ICTs in education is an inevitable requirement that students and teachers in language classrooms become "multiliterate." This means, apart from a conventional literacy of the target language [24], they have to take up new digital literacies $[25,26]$. These electronic literacies, stated Warschauer [27, p.455] based on his earlier works in 1999 and 2000, consist of four closely related elements:

- Computer literacy: comfort and fluency in keyboarding and using computer;

- Information literacy: the ability to find and critically evaluate online information;

- Multimedia literacy: the ability to produce and interpret complex documents comprising texts, images, and sounds; and

- Computer-mediated communication literacy: knowledge of the pragmatics of individual and group online interaction.

Very briefly, being digitally literate means being able to function effectively as literate citizens in digital environments [28]. Weblogs make a good example for what is meant by multiliteracies in the context of Web 2.0. Blogs users need not only language and cultural competence to make sense of the content and context of many blog posts [29] but also computer and Internet proficiency for creating and managing their Internet-based teaching and learning [30]. On the one hand, such combination of writing and online technology offers students and educators with chances to both enhance traditional literacy skills and build up their digital fluency [31]. On the other hand, it raises concerns about teachers being mounted up with responsibilities and uncertainties, as they are urged to adapt themselves to the use of new technologies in administration, lesson planning, collaborating with colleagues, and as teaching aids for classroom use [2]. Multiliteracies in language teaching and learning, therefore, brings with it a major cultural shift that changes teachers" professional identity and literacy practices. 


\subsection{The not-so-ICT-Competent "Digital Natives"}

As inferred from earlier analyses, the worldwide development of ICTs is the main attribution for the formation of a new student generation referred to as "digital natives" [32], or Generation Z (young people born between 1995 to 2015) and now "Generation Alpha" (children born between 2011, now, and into 2025) [33]. Generally, the terms are associated with the image of students who are sophisticated and competent in ICTs, or who are, in Prensky's words, the "native speakers of the digital language of computers [...] and the Internet" $(32$, p.1). Immersed in a technologyrich culture, they are claimed to be active and proficient learners who are capable of multitasking, accessing information and interacting with others by means of communications technologies [34].

However, are the so-called Netizens really digitally competent? Educational practitioners start to question this when putting together recent research outcomes in the field of ICT-enhanced education. Scanlon [35] found out the majority of his "digital natives" approached computers cautiously and indeed experienced no less frustrations with computers than older students. Participants in Stolle and Fischman's study [36] also shared that though being able to provide teachers with certain technological aids, students still lack academic knowledge about multiliteracies and effective use of digital technologies. Similarly, Ransdell et al [37] concluded that their millennial students, i.e. born 1982+, showed poorer knowledge application skill and being less active in websites associated with the online courses compared to previous generations of students. More recently, Alonso and Samy [38] also reported limited digital competence of the foreign language students who participated in a MOOC (Massive Open Online Course) despite their regular use of the Internet and ICT. Their difficulties ranged from differentiating between registering on the platform and enrolling in the corresponding MOOC to using different accounts to follow the course and feeling lost among platforms.

The above examples indicate a significant proportion of young college students who lag behind the levels of access or technology skills that "digital natives" are supposed to have. The divergence between claims about a Net generation and what really happens in the classroom, explained Scanlon [35], varies according to students' economic background and their affinity with computers and technologies. Consequently, researchers aiming at curriculum innovations with new technologies are highly recommended to consider the significant variability in learners' and practitioners' confidence with ICT as well as their unequal access to the technology [39] to make sure the technology-driven activities would be fruitful.

\subsection{Changes in Professional Indentity and Role of Teachers in ICT-Enhanced Classrooms} disruption

- Teachers' fear of professional identity

Teachers derive their professional identity from the way they see themselves as subject matter experts, pedagogical experts, and didactical experts; this construction of identity is never separable from their interactions with students [40]. For a long time, teachers had been perceived as the sole depositors of knowledge having full authority over students, the depositories [41].

However, the emergence of a "digital native" generation of students having both "access to networked digital technologies" and "the skills to use those technologies" [42, p.1] has given rise to the redefinition of most teachers" identity as "digital immigrants" for their greatly different experience with technologies from that of students [32]. These redefined social identities of teachers and students seriously altered the traditional power structure in language classrooms and, in some circumstances, even repositioned students as the ones in-the-know [36]. As a result, many teachers find themselves struggling between 
retaining the conventional power structure in their classrooms and trying to fit in the new technology-enhanced environment, i.e. take up new skills, behaviours and attitudes while putting aside others [43]. Gradually, they develop feelings of having their sense of self challenged and their professional identity disrupted [44].

Disruptions of traditional teacher identity are noticeable "when the digitally immigrant teachers lack adequate knowledge for the task at hand and attempt to use digital technologies in new and unfamiliar ways" [36, p.162]. Indeed, the more significant the disrupted identity is, the more stressful experience teachers have to undergo [43]. This explains the reluctance or even resistance of many language teachers in adopting new technologies in their classroom despite the promising pedagogical benefits of ICT integration. teachers

- Heightened rather than diminishing role of

Admittedly, ICT-integration process may, to some extent, changes the ways teachers communicate, construct knowledge and how they make and ascribe meaning, but it actually heightens rather than minimizes teachers' roles in their own classrooms. First and foremost, the diversity in students' aptitude [45, 46] and attitudes [47] requires special sensitivity on the part of the teacher or administrator in designing appropriate online activities that meet the specific needs of learners. At the same time, this emphasizes the importance of teachers in integrating knowledge of teaching strategies with an understanding of features of online learning and providing an ideal learner-centred environment in which students were given the right to control and monitor their performance [48].

Second, regardless of being "digital natives" or not, students still face feelings of isolation or lost in technologies [38]. A case in point was Kung's [49] study, in which up to $70 \%$ of the students in the BALL (Blog-assisted language learning) writing course reported some degree of isolation in class and were concerned about the lack of face-to-face interaction with their teacher for more detailed and personal feedback. Since new ICTs make up "a broader ecology of life" with much of the written and oral communication from other environments migrated to the screen [50, p.307], teachers should participate in and guide students' communication and learning by scaffolding with their own knowledge and experience [51] so that they can work and learn with instructional technology [48]. Moreover, regarding the overgeneralization of the whole Net generation, the role of language teachers should be emphasized in designing appropriate tasks to build up students' multiliteracies competence as well as maintaining a relatively equal access to technology among students.

\section{Conclusion}

As the adoption of ICTs in education moves to its third stage of discontinuous innovation [5], a wide range of asynchronous and synchronous tools, including web 2.0, have been given credits for their pedagogic benefits. However, the employment of ICTs in language teaching brings with it a challenge of "multiliteracies" in which both teachers and students are required to function as literate citizens in digital environment [25]. Besides, the use of new and unfamiliar technologies might arouse the fear of professional identity disruption in a part of language teachers, leading to their reluctance to adopt. Furthermore, the fact that not all of the students are ICT-competent underlines the need for an innovative but inclusive language curriculum, i.e. one that also considers those less interested and less able in ICTs as well as potential impacts of socio-economic and cultural factors resulting from ICT adoption. Most importantly, digital competent or not, language teachers retain the key factor in any ICT-enhanced classrooms for their role in promoting meaningful interactions and real intercultural reflections beyond the conventional language classroom. 


\section{References}

[1] E.J. Evans, Autonomous literacy or social practice? Students" constructions of technology literacy Journal of Literacy and Technology 5(1) (2005) 1-39.

[2] J. McDougall, A crisis of professional identity: How primary teachers are coming to terms with changing views of literacy, Teaching and Teacher Education 26 (2009) 679-687.

[3] K. Moyle, Computing technologies in school education: Policies and standards and standard policies, Sydney: Australian Association of Research in Education (AARE) annual conference, 2005.

[4] A.B.M. Tsui, J.W. Tollefson, Language policy and the construction of national cultural identity, In A.B.M. Tsui and J.W. Tollefson (Eds.), Language policy, culture, and identity in Asian contexts, Mahwah, NJ: Lawrence Erlbaum Associates Publishers, 2007, pp. 1-21.

[5] R.L. Celsi, M. Wolfinbarger, Discontinuous classroom innovation: Waves of change for marketing education, Journal of Marketing Education 24(1) (2002) 64-72.

[6] K. Graves, The language curriculum: A social contextual perspective, Language Teaching 41(2) (2008) 147-181.

[7] M. Rasulo, The role of community formation in learning processes, In M. Thomas (Ed.), Handbook of research on web 2.0 and second language learning, Hershey, USA: Information Science Reference, 2009, pp. 80-100.

[8] D.E. Murray, Technologies for second language literacy, Annual review of applied linguistics 25 (2005) 188-201.

[9] M. Warschauer, P.E. Whittaker, The Internet for English teaching: Guidelines for teachers, In J.C. Richards \& W.A. Renandya (Eds.), Methodology in language teaching: An anthology of current practice, Cambridge: Cambridge University Press, 2002.

[10] M. Warschauer, Motivational aspects of using computer for writing and communication, Paper presented at the Telecollaboration in foreign language learning: Proceedings of the Hawaii symposium, Honolulu, 1996.

[11] M.K. Ahmad, A.H.M. Adnan, N.M. Azamri, K.B. Idris, N.N. Norafand, N.I. Ishak, Education 4.0 technologies for English language teaching and learning in the Malaysian context, Paper presented at the International Invention, Innovative \& Creative (InIIC) Conference, 2019, Senawang: MNNF Network, 2019.

[12] R. Eynon, The use of the internet in higher education: Academics' experiences of using ICTs for teaching and learning. Paper presented at the Aslib Proceedings: New Information Perspective, 2005.

[13] R.C. Li, R.S. Hart, What can the World Wide Web ofer ESL teachers? In J.C. Richards, W.A. Renandya (Eds.), Methodology in language teaching: An anthology of current practice. Cambridge: Cambridge University Press, 2002.

[14] A. Gilmore, Authentic materials and authenticity in foreign language learning, Language Teaching, 40(2) (2007) 97-118.

[15] A. Gilmore, "I Prefer Not Text": Developing Japanese Learners" Communicative Competence with Authentic Materials. Language Learning, 2011, pp. 1-34.

[16] F. Dubin, E. Olshtain, Course Design. Cambridge: Cambridge University Press, 1986.

[17] J.I.A. Gómez, E.L.P. Meneses, L.A. Díaz, Innovating with blogs in university courses: a qualitative study, The New Educational Review, 22(8) (2010) 103-116.

[18] G. Genç, S. Aydin, Students' motivation toward computer-based language learning, International Journal of Educational Reform 20(2) (2011) 171-189.

[19] N. Hara, Student distress in a web-based distance education course. Information, Communication \& Society 4(3) (2000) 557-679.

[20] J. Bauer, J. Kenton, Toward technology integration in the schools: Why it isn't happening. Journal of Technology and Teacher Education, 13(4) (2005) 519-546.

[21] W. Mei-jung, The current practice of integration of information communication technology to English teaching and the emotions involved in blended learning. The Turkish Online Journal of Educational Technology 13(3) (2014) 188-201.

[22] G. Azzaro, J.D.D.M. Agudo, The emotions involved in the integration of ICT into L2 teaching: Emotional challenges faced by L2 teachers and implications for teacher education, In Agudo, J.D.M (Ed.), Emotions in Second Language Teaching: Springer International Publishing AG, 2018, pp. 183-203.

[23] M. Baguley., D.L. Pullen., M. Short, Multiliteracies and the new world order. In D. L. Pullen \& D. R. Cole (Eds.), Multiliteracies and technology enhanced education:Social practice and the global classroom, New York: Information Science Reference, 2010, pp. 1-17.

[24] W.S.E. Lam, L2 literacy and the design of the Self: A case study of a teenager writing on the Internet. TESOL Quarterly, 34(3) (2000) 457-482.

[25] P. Gilster, Digital literacy. New York: John Wiley \& Sons, 1997. 
[26] R. Iyer, C. Luke, Multimodal, multiliteracies: Texts and literacies for the 21 st century. In D. L. Pullen \& D. R. Cole (Eds.), Multiliteracies and technology enhanced education: Social practice and the global classroom, Hershey, USA: Information Science Reference, 2000.

[27] M. Warschauer, A developmental perspective on technology in language education, TESOL Quarterly, 36(3) (2002) 453-475.

[28] G.E. Hawisher, C.L. Selfe, B. Moraski, M. Pearson, Becoming literate in the information age: cultural ecologies and the literacies of technology. College Composition and Communication 55(4) (2004) 642-692.

[29] T. Raith, The use of weblogs in language education. In M. Thomas (Ed.), Handbook of research on Web 2.0 and second language learning, Hershey: Information Science Reference, 2009, pp. 274-291.

[30] N. Carney, Blogging in foreign language education. In M. Thomas (Ed.), Handbook of research on web 2.0 and second language learning Hershey: Information Science Reference, 2009, pp. 292-312.

[31] S. Witte, "That's online writing, not boring school writing": Writing with blogs and the Talkback project, Journal of Adolescent \& Adult Literacy, 51(2) (2007) 82-86.

[32] M. Prensky, Digital natives, digital immigrants, On the Horizon 9(5) (2001) 1-6.

[33] M.K. Ahmad, A.H.M. Adnan, N.M. Azamri, K.B. Idris, N.N. Norafand, N.I. Ishak, Education 4.0 technologies for English language teaching and learning in the Malaysian context, Paper presented at the International Invention, Innovative \& Creative (InIIC) Conference, 2019, Senawang: MNNF Network, 2019.

[34] S. Bennett, K. Maton, K. Kervin, The "digital natives" debate: A critical review of the evidence. British Journal of Educational Technology 39(5) (2008) 775-786.

[35] C.B. Scanlon, The natives aren"t quite so restless. Sydney: The Australian, 2009.

[36] E.P. Stolle, G.E. Fischman, Disrupting traditions: Teacher negotiating multiliteracies and digital technologies. In D. R. Cole \& D. L. Pullen (Eds.), Multiliteracies in motion, New York and London: Routledge, 2010, pp. 160-172.

[37] S. Ransdell, B. Kent, S. Gaillard-Kenney, J. Long, Digital immigrants fare better than digital natives due to social reliance, British Journal of Educational Technology 42(6) (2011) 931-938.

[38] J.L.G. Alonso, D. Samy, Applicability of ICTsupported language teaching in contexts of social integration and international cooperation, Círculo de Lingüística Aplicada a la Comunicación 76 (2018) 101-116.

[39] B.B.N. Prasad, Scaffolding English language learning with information and communication technology. IMPACT: International Journal of Research in Humanities, Arts and Literature 5(12) (2017) 13-18.

[40] D. Beijaard, N. Verloop, J.D. Vermunt, Teachers' perceptions of professional identity: An exploratory study from a personal knowledge perspective, Teaching and Teacher Education 16 (2000) 749-764.

[41] P. Freire, Pedagogy of the oppressed. New York: Continuum, 1970.

[42] J.G. Palfrey, U. Gasser, Born digital: Understanding the first generation of digital natives, New York: Basic Books, 2008.

[43] H. Nach, A. Lejeune, Coping with information technology challenges to identity: A theoretical framework. Computers in Human Behavior 26 (2010) 618-629.

[44] R. Lamb, E. Davidson, Information and communication technology challenges to scientific professional identity, The Information Society 21(1) (2005) 1-24.

[45] L.V. Nguyen, Technology-enhanced EFL syllabus design and materials development, English Language Teaching 1(2) (2008a) 135-142.

[46] L.V. Nguyen, The triangular issues in multimedia language courseware design in the Vietnamese EFL environment, Asian Social Science 4(6) (2008b) 65-67.

[47] T.T. Dang, M. Robertson, E-behaviors and E-community Formation: An Investigation on Vietnamese EFL Students, The Asian EFL Journal 46(1) (2010) 4-27.

[48] C. Buzzard, V.L. Crittenden, W.F. Crittenden, P. McCarty, The use of digital technologies in the classroom: A teaching and learning perspective, Journal of Marketing Education 33(2) (2011) 131-139.

[49] F.W. Kung, Assessing an innovative advanced academic writing course through blog-assisted language learning: Issues and resolutions, Innovations in Education and Teaching International, 2015, pp. 1-9.

[50] M. Warschauer, C. Meskill, Technology and second language teaching, In J. W. Rosenthal (Ed.), Handbook of undergraduate second language education, New Jersey: Lawrence Erlbaum Associates, Publishers, 2000, pp. 303-318.

[51] J. Stepp-Greany, Student perceptions on language learning in a technological environment: Implications for the new millennium, Language Learning \& Technology 6(1) (2002) 165-180. 